\title{
Authentic Learning in Distance Education Special Issue
}

\section{Charles B. Hodges ${ }^{1}$}

Published online: 9 June 2020

(C) Association for Educational Communications \& Technology 2020

This issue of the TechTrends, is a special issue guest edited by Victoria L. Lowell and Linda L. Campion on the topic of authentic learning via distance education. They have put together a great issue for you containing eleven papers. Their Guest Editors' Notes provides a detailed introduction to the issue. I appreciate the months of hard work and collaboration they did to make this issue a reality! I also appreciate the authors who submitted their work to the issue! With much of higher education in the world now shifting more toward online delivery of instruction due to the pandemic, the issue is appearing with amazingly good timing.

The issue also includes some of our regular columns. Be sure to read the Rethinking Technology \& Creativity in the 21st, Graduate Member Musings, The History Corner, and Book Reviews. I hope you find the issue interesting!
As always, if you are interested in submitting a manuscript to TechTrends, or if you want to be a reviewer, please contact me. Encourage your colleagues to submit their work to TechTrends, to read TechTrends, and to consider joining AECT! If you have a question about the journal, my phone number is $912-478-0497$ and my email address is chodges@georgiasouthern.edu. Email is always the best way to reach me. Also, you can follow TechTrends on Twitter: @AECTTechTrends.

Publisher's Note Springer Nature remains neutral with regard to jurisdictional claims in published maps and institutional affiliations.

Charles B. Hodges

chodges@georgiasouthern.edu

1 Georgia Southern University, Statesboro, GA, USA 